\title{
A Study on Teacher Support and Learning Adaptation among Six- year Normal University Freshmen: The Moderating Effect of the Hardiness
}

\author{
Jian-Yong Chen ${ }^{1,2}$, Chia-Ching Tu ${ }^{3^{*}}$ \\ ${ }^{1}$ Dhurakij Pundit University, THAILAND \\ ${ }^{2}$ Hunan University of Arts and Science, CHINA \\ ${ }^{3}$ Department of Education Management, CAIC, Dhurakij Pundit University, Bangkok, THAILAND
}

Received 11 September 2019 - Revised 10 November 2019 - Accepted 20 November 2019

\begin{abstract}
In this study, the teacher support scale, the hardiness scale and the learning adaptation scale were used in a kindergarten teacher's college in Changde. A survey was conducted among 1148 college students to analyze the relationship between teacher support, hardiness and learning adaptation, and to explore whether hardiness plays a role in the moderation between teacher support and learning adaptation. The result is that: (1) Teacher support can significantly predict students' learning adaptation; (2) Hardiness can also be significant predication of students' learning adaptation; (3) Hardiness can play a moderator role in teacher support and learning adaptation. I conclude by acknowledging the limitations of this study and recommending further research.
\end{abstract}

Keywords: teacher support, learning adaptation, hardiness, moderating

\section{INTRODUCTION}

Piaget holds the view that the nature of wisdom is an adaptation to biology. The organism adapts to the environment by assimilation and adaptation in its constant motion. If the body is out of balance with the environment, the behavior needs to be changed to rebuild the balance. This dynamic process is adaptability. Domestic scholars have various interpretations of the concept of adaptability. Zheng (1994) believes that "adaptability is the psychological ability, that is, the individual interacts with the surrounding environment, and reacts actively to the surrounding environment in a certain way in the process of interacting with the surrounding people to obtain the balanced psychological capability" Xu (2000). From the perspective of social psychology, it is considered that adaptability is "the ability of an individual to form a corresponding psycho-behavioral pattern in order to complete a certain process of social adaptation." According to Zhang, Feng, Guo, and Chen (2000), adaptability refers to "an individual's ability to change himself or his environment in the process of socialization, so that he or she can coordinate with the environment." In The Encyclopedia of Psychological Counseling Che (2001) points out that adaptability is "the ability of individuals to change their survival, development and goal accordingly in the change of social organization, group or cultural economic factors."

Learning adaptation is a tendency for individuals to overcome various difficulties, meet the needs and adapt to the changes in the environment in their learning process in order to achieve better academic achievements (Chen, Wang, \& Cao, 2011). According to Feng Tingyong, Li Hongren (2002), learning adaptation is "a psychological and behavioral process in which the main body, according to the needs of the environment and learning, tries to adjust the self to achieve a balance with the learning environment."

Previous studies have found that the more teacher support the teenagers perceive, the better they can adapt to their learning. At the same time, the relationship between them may also be influenced by personality and other internal characteristics of the individual. Whether the five-year normal school students can adapt well is not only closely related to their personal physical and mental health and career development, but also may affect the quality

(C) 2019 by the authors; licensee Modestum Ltd., UK. This article is an open access article distributed under the terms and conditions of the Creative Commons Attribution License (http://creativecommons.org/licenses/by/4.0/). 凹1151923468@qq.com 《2575938094@qq.com (*Correspondence) 


\section{Contribution of this paper to the literature}

- From the perspective of personality, this study explores the influence of teacher's support on the learning adaptation of specific groups of college students with the purpose of providing reference for higher education reform and theoretical support for the sustainable development of teacher vocational education.

of primary education in rural areas of China ( $\mathrm{He} \& \mathrm{Hu}$, 2017). The students enrolled for five-year teacher education are from rural junior high school. They are far away from home and live in the city. Whether the new living environment will affect their learning inadaptability is still a question. Normal school students also need to change their exam-oriented learning habit in the middle school to adapt to the new curriculum and new requirements of the normal school. But studies on the learning adaptability of five-year normal education are rarely seen at present, which deserves further study.

Deci and Ryan (2004) believe that learning in a teacher-supported environment can enhance students' selfmotivation and learning initiative, and promote students to actively mobilize their interest in learning, and further expand their perceived teacher support, and manage their learning behavior and time, use learning strategies, and they can be responsible for their learning results. Wentzel (2009) holds that every student, from the personal experience, can feel how different teachers are like: some are easy to talk to, while others seem boring. According to Ahmed, Minnaert, Van der Werf, and Kuyper (2010), Ansong, Okumu, Bowen, Walker, and Eisensmith (2017), among many teacher supports, a good teacher-student relationship can help students overcome the adverse environmental impact and is the most effective strategy to cultivate and stimulate students' learning motivation. Teachers can provide students with different types of help, with the focus of learning on academy and emotion. Reddy, Rhodes and Mulhall (2003) studied the relationship between teacher support and learning adaptability. (Garcia-Reid \& Peterson, 2005). The study also confirms the importance of teacher support on students' academic input. Onuoha (2015) found that teachers support plays a positive role in helping students to complete the curriculum, while limiting their participation in dangerous actions. Xiao (2016) studies the relationship between teacher support and school adaptation. Researches have shown that teacher support is one of the variables closely related to learning adaptation.

As an important variable, what is the relationship between hardiness and other variables in this study? According to Maddi $(1998,2002,2006)$, hardiness originates from existentialist psychology. It is a combination of action and its goal is to develop and survive to enrich life. The study also found that hardiness is a kind of function and an important regulator or buffer in stress-health relationships. Kobasa (1979) initially defined hardiness as the ability to protect individuals from the health effects of stress. He proposed three aspects of personality structure: commitment, control and challenge. But Costantini, Solano, Di and Bosco (1997) argue that "cognitive and behavioral flexibility, motivation for successful implementation of the plan, and endurance of stress are all characteristics of hardiness." Smith, (Young \& Lee, 2004) also pointed out that hardy individuals should have "the ability to withstand sustained physical and psychological suffering, the ability to resist stress and difficulty, and have the courage and boldness for adventure, the ability to control, exert power and influence others."

What's the link between teacher support and learning adaptation? Deci and Ryan (1985) holds that the teacher support that students perceive is that they feel the teacher agrees with their choice and decision, they can get valuable information from the teacher, get the recognition of emotional experience and feel less pressure.

In terms of hardiness and learning adaptation, Compas, Connorsmith, Saltzman, Thomsen and Wadsworth (2001) think of learning adaptation as one of the most important forms of adaptation, which is closely related to mental health. Maddi, Harvey, Khoshaba, Fazel, and Resurreccion (2012) confirm the expectation that hardiness is the core factor in school performance. Yu (2007) holds that bad school adaptation often produces inferiority, loneliness and other psychological problems. In many researches of school adaptation, personality factor is the variable that scholars pay more attention to. Previous studies have found that personality is an important factor affecting school adaptation, and it can effectively predict the learning adaptation of freshmen. Sun and Fu (2016) believes that hardiness is seen as an important factor in promoting individual's better adaptation to society. Li, Zou and Zhao (2003) think the hardiness has a stimulating effect on the active school adaptation of the college students and can prevent the negative school adaptation. Tao (2003) found that hardiness level has a direct influence on students' adaptation, and personality has a dynamic relationship with individual adaptation.

In terms of hardiness and teacher support, according to Ghorbani, Watson, and Morris (2000) as is expected, hardiness is positively correlated with problem-solving, social support interactions, and beneficial self-care efforts. Other studies, such as the life span theory, are consistent with these findings. Life-span theory holds that social support is related to the personality trait of the adaptability, and the improved personality facilitates more support and self-efficacy. According to Tan (2011), the total score of social support plays a significant role in predicting mental hardiness. 


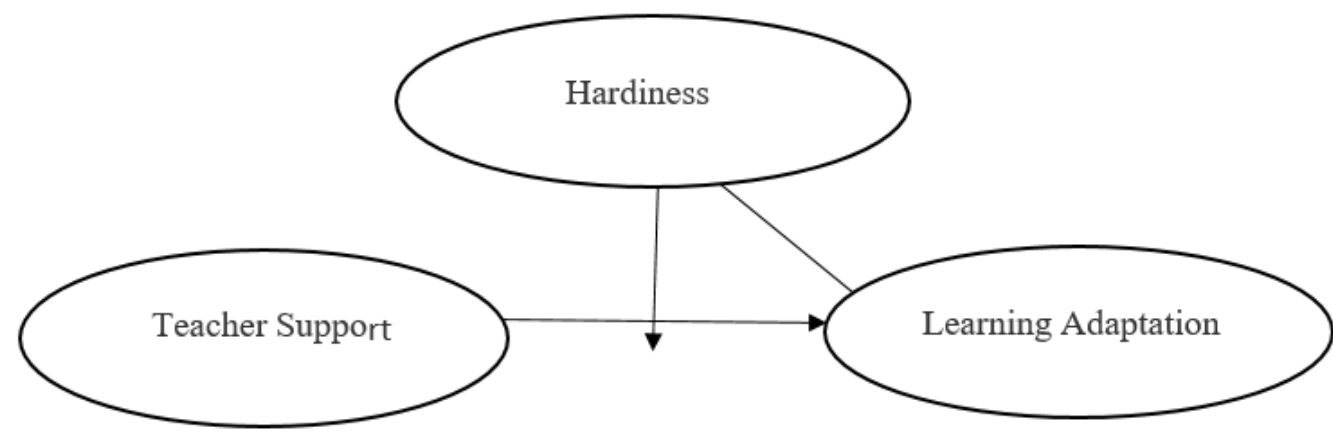

Figure 1. Research Framework

Table 1. Description and Analysis of basic Information under investigation

\begin{tabular}{llll}
\hline Attribute & Category & Number of persons & $\%$ \\
\cline { 2 - 4 } Gender & Male & 336 & 29.3 \\
\hline \multirow{2}{*}{ Location } & Rural areas & 812 & 70.7 \\
\cline { 2 - 4 } & Market town & 506 & 44.1 \\
\hline
\end{tabular}

Does hardiness play a moderating role in teacher support and learning adaptation? What effect can it achieve? This is a problem that needs to be excavated and studied. Based on hardiness theory model, research diagram shown in Figure 1 is proposed.

To sum up, this study investigated the effects of teacher support on learning adaptation and explored the moderation role of hardiness in the relationship among six-year normal university freshmen. As is shown in Figure 1, this study assumes that: (1) teacher support can directly predict their learning adaptation; (2) hardiness can directly predict learning adaptation; and (3) hardiness plays a moderation role in the relationship between teacher support and learning adaptation.

\section{METHOD}

\section{Subjects}

This research adopts the method of cluster sampling, with the leaders of the school and the counselors participating in the whole process. As the subjects of this study, the trained head teacher reads the instruction to the student and makes some explanation, and then conducts a test in the class. 1151 questionnaires were issued with 1148 questionnaires collected. The questionnaire consists of three parts and the effective rate of the questionnaire is $99 \%$. The age of the subjects was between 14 and 17 , with an average age of16. 13 years $(\mathrm{SD}=0$. 934). Among them, there are 336 boys and 812 girls accounting for $29.3 \%$ and $70.7 \%$ respectively; students from rural areas account for $44.1 \%$ while that of market town $55.9 \%$; the only child takes up $68.6 \%$ and the rest $31.4 \%$.

Table 1 shows the details.

\section{Research Tool}

\section{The scale and measurement of learning adaptation}

In this study, twenty-nine items were selected from the College Students' Learning Adaptation Scale by Feng et al. (2006) in terms of five dimensions: (1) 8 items on learning motivation (2) 7 items on teaching modes (3) 6 items on learning abilities (4) 4 items on learning attitudes (5) 4 items on environmental factors. Five scales are adopted, from "very disagree" to "agree very much", scoring 1 5 separately. The higher the total score is, the higher the learning adaptability they feel. The analysis of the results by confirmatory six-factor model shows that $\mathrm{x}^{2} / \mathrm{df}=2.711$, RMSEA $=0.039$, GFI $=0.942, \mathrm{CFI}=0.967$, indicating the scale data and theoretical model are perfectly matched. As is obtained from Table 2, the sub-dimension Cronbach's Alpha values of learning motivation, teaching mode, learning ability, learning attitude and environmental factors are $0.919,0.901,0.878,0.866$ and 0.857 respectively. They are all over 0.7 , meeting the requirements of reliability test. The total a coefficient in the scale of this study is 0.943 . 
Table 2. Analysis of teacher support reliability

\begin{tabular}{lccc}
\hline Variables & CR & Cronbach's Alpha & AVE \\
\hline Learning motivation & 0.919 & 0.919 & 0.588 \\
\hline Teaching mode & 0.907 & 0.901 & 0.584 \\
\hline Learning ability & 0.88 & 0.878 & 0.55 \\
\hline Learning attitude & 0.869 & 0.866 & 0.625 \\
\hline Environmental factors & 0.858 & 0.857 & 0.601 \\
\hline Learning adaptation & 0.859 & 0.943 & 0.55 \\
\hline
\end{tabular}

Table 3. Analysis of teacher support reliability

\begin{tabular}{lccc}
\hline Variables & CR & Cronbach's Alpha & AVE \\
\hline learning support & 0.93 & 0.929 & 0.595 \\
\hline Emotional support & 0.898 & 0.897 & 0.596 \\
\hline Capability support & 0.889 & 0.889 & 0.688 \\
\hline Teacher support & 0.816 & 0.937 & 0.597 \\
\hline
\end{tabular}

Table 4. Analysis of hardiness reliability

\begin{tabular}{lccc}
\hline Variables & CR & Cronbach's Alpha & AVE \\
\hline Control & 0.92 & 0.919 & 0.589 \\
\hline Challenge & 0.88 & 0.877 & 0.514 \\
\hline Input & 0.577 & 0.875 & 0.543 \\
\hline Toughness & 0.888 & 0.886 & 0.57 \\
\hline Hardiness & 0.842 & 0.939 & 0.573 \\
\hline
\end{tabular}

\section{Teacher support scale and measurement}

In this study, the teacher support students perceived was measured by questionnaire. Ouyang (2005) selfcompiled the teacher support scale based on Babad et al. (1990) on that of teacher's differential behavior, in which there are 19 items from three basic dimensions: emotional support, capability support and learning support. (1) 9 items on learning support; (2) 6 items on emotion support; (3) 4 items on capability support, from "very disagree" to "agree very much", scoring 1 5 separately. The higher the total score is, the more teacher support they perceived. A four-factor model is adopted in the confirmatory factor analysis. The result shows that $\mathrm{x}^{2} / \mathrm{df}=3.75, \mathrm{RMSEA}=0.049$, GFI=0.952, CFI=0. 970, indicating the scale data and theoretical models matched well. The sub-dimension Cronbach's Alpha values of learning support, emotional support, ability support are $0.929,0.897$ and 0.889 respectively. They are all over 0.7 , meeting the requirements of reliability test. The total a coefficient in the scale of this study is 0.937 .

\section{The scale and measurement of hardiness}

Hardiness was originally described as a personality style or pattern by Kobasa (1979). A person can maintain good health and perform well under pressure. The scale by Kobasa (1982) consists of 27 subjects from three dimensions: commitment, control and challenge. Authorizing PVS111-R Scale by Maddi, translated by Lu and Liang (2008) and approved by the original author, the Chinese version of the questionnaire is generated. Compiled by Lu and Liang (2008), the Chinese version of the Mental Hardiness Scale was revised, which contains a total of 27 items and four dimensions accord with the characteristics of the Chinese people: (1) 8 items on control, (2) 7 items on challenges, (3) 6 items on input, (4) 6 items on hardiness. This edition is selected to carry on the research. Analysis results of confirmatory factor Four-factor model show that $x^{2} / \mathrm{df}=2.693$, RMSEA $=0.038$, GFI $=0.948$, $\mathrm{CFI}=0.968$, indicating the scale data and theoretical model have a good match. The sub-dimension Cronbach's Alpha values of control, challenge and input are $0.919,0.877,0.875$ and 0.886 respectively. They are all over 0.7 , meeting the requirements of reliability test. The total a coefficient in this scale is 0.939 , which shows a good reliability on the whole. 
Table 5. Correlation analyses of the main variables

\begin{tabular}{lcccccccc}
\hline & $\mathbf{M}$ & SD & $\mathbf{1}$ & $\mathbf{2}$ & $\mathbf{3}$ & $\mathbf{4}$ & $\mathbf{5}$ & $\mathbf{6}$ \\
\hline 1. Gender & 1.707 & 0.455 & - & & & & & \\
\hline 2. Location & 1.559 & 0.497 & -0.004 & - & & & & \\
\hline 3. Only child & 0.686 & 0.465 & 0.03 & 0.018 & - & & \\
\hline 4. Teachers support & 3.500 & 0.857 & 0.041 & 0.036 & $.103^{* *}$ & $(\mathbf{0 . 7 7 3})$ & \\
\hline 5. Hardiness & 3.633 & 0.716 & 0.05 & 0.012 & $.087^{\text {** }}$ & $.537^{\text {** }}$ & $(\mathbf{0 . 7 5 7})$ & \\
\hline 6. Learning adaptation & 3.674 & 0.717 & 0.045 & 0.02 & $.072^{*}$ & $.586^{* *}$ & $.518^{* *}$ & $(\mathbf{0 . 7 4 2})$ \\
\hline
\end{tabular}

\section{RESEARCH RESULTS}

\section{Data Analysis}

SPSS 22.0 is adopted in data input, collation and correlation analysis; the demographic variables in the study are analyzed and processed by virtual coding; and AMOS22 is used to do confirmatory factor analysis, and regulatory model analysis and non-parametric percentile test were performed.

\section{Common Method Biases Tests}

In order to avoid the common method biases caused by the research method, anonymity and confidentiality are adopted in the process of data collection. Harman's single factor test was used to check the range of biases of the common method (Podsakoff et al., 2003). All three variables, teacher support, hardiness and learning adaptation, were put into an exploratory factor analysis to test the results of factor analysis without rotation. Through Harman's single factor analysis of unrotated principal component factors, it was found that the characteristic root value of 12 factors was over 1 , and the variation of the first factor was only $17.7 \%$, less than critical standard $40 \%$ (Zhou \& Long, 2004), which shows that there is no obvious common method biases in this study.

\section{Correlation Analyses of the Variables}

The correlation coefficients of teacher support, hardiness and learning adaptation were calculated by Pearson. The results were shown in the table. The results of correlation analysis showed that teacher support was positively correlated with learning adaptation, and hardiness was positively correlated with learning adaptation. Through validity analyses and reliability analyses, the structure of the dimension and the corresponding problems are determined. The average value of each dimension is calculated as the score of the dimension, and then the correlation analyses is carried out. Correlation analyses are mainly to study the correlation between variables, and the range of correlation coefficient is between -1 and 1 ; the larger the absolute value is, the closer the correlation between variables is. In this study, gender, location, only child, teacher support, hardiness, learning adaptation were analyzed, as is shown in Table 5 .

There is a significant positive correlation between teacher support and learning adaptation $(r=0.586, p<0.01)$ and hardiness has significant positive correlation with learning adaptation $(r=0.518, p<0.01)$. Regression analyses will be used to further study the relationship between them.

\section{The Moderation of Hardiness in Teacher Support and School Adaptation}

In order to control the influence of demographic variables, we use gender, location, only child as control variables, teacher support as independent variables, hardiness as adjustment variables, learning adaptation as dependent variables and hierarchical regression analyses is adopted. The first layer includes demographic variables, the second layer independent variables and regulatory variables, and the third layer the interactions between independent variables and moderation variables. Table 6 shows the specific effects of college students' hardiness on the relationship between stress and learning adaptation. In model 2 , the effect of teacher support on learning adaptation was significant $(\beta=0.584, \mathrm{p}<0.001)$. In model 3 , the effect of teacher support on learning adaptation $(\beta=0.285, p<0.001)$ was still significant, which is obviously affected by the tough personality variable. The effect of teacher support on learning adaptation is still significant in model $4(\beta=0.447, p<0.001)$, which has a regulatory effect because of the teacher supports and the product of regulatory variables. 
Table 6. The moderation effect of hardiness

\begin{tabular}{|c|c|c|c|c|}
\hline & \multicolumn{4}{|c|}{ Learning Adaptation } \\
\hline & M1 & M2 & M3 & M4 \\
\hline & $\beta$ & $\beta$ & $\beta$ & $\beta$ \\
\hline Gender & 0.043 & 0.021 & 0.013 & 0.012 \\
\hline Location & 0.019 & -0.001 & 0.001 & -0.001 \\
\hline Only child & $0.071^{*}$ & 0.011 & 0.003 & -0.012 \\
\hline teacher supports & & $0.584^{\star \star \star}$ & $0.432^{\star \star \star}$ & $0.447^{\star \star \star}$ \\
\hline Hardiness & & & $0.285^{\star \star *}$ & $0.361^{* * *}$ \\
\hline Hardiness with teacher support & & & & $0.239 * * *$ \\
\hline R side & 0.007 & 0.343 & 0.401 & 0.451 \\
\hline Adjusted R side & 0.005 & 0.341 & 0.399 & 0.448 \\
\hline $\mathrm{F}$ & $2.863^{*}$ & $149.493^{\text {*** }}$ & $153.028^{\star * *}$ & $156.286^{\star \star *}$ \\
\hline
\end{tabular}

Note: ${ }^{*} p<0.05 ;{ }^{* *} p<0.01 ;{ }^{* * *} p<0.001$

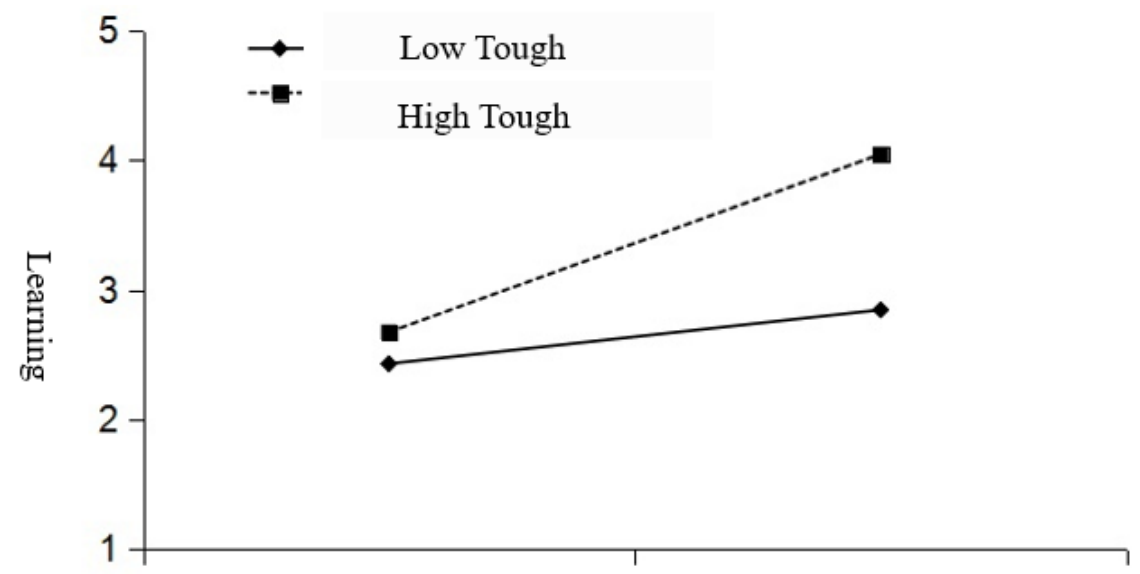

\section{Low Teacher}

Figure 2. The effect of moderation

High Teacher

From model 3 above, R squared is 0.401 , indicating that teacher support and hardiness can explain $40.1 \%$ biases of learning adaptation, teacher support $(\beta=0.432, p<0.001)$ and hardiness $(\beta=0.2855, P<0.01) . P<0.001$ can significantly predict learning adaptation. After considering the mediation of hardiness in model 4 , the total explanatory variation of learning adaptation increased to $45.1 \%$, and the adjustment effect of hardiness was significant $(\beta=0.239, \mathrm{p}<0.001)$. At this point, teacher support had significant positive effects on learning adaptation $(\beta=0.447, p<0.001)$ and on hardiness $(\beta=0.361, p<0.001)$. Therefore, hypothesis $1,2,3$ were confirmed.

From model 4 above, it can be concluded that with teacher support, hardiness has a significant positive effect on learning adaptation $(\beta=0.239, p<0.001)$, indicating that hardiness plays a positive role in the effect of teacher support on learning adaptation, and the hypothesis is valid. The adjustment effect diagram is shown in Figure 2.

According to Table 6, it can be seen that hardiness can adjust the relationship between the teacher and the college students' learning adaptation, that is, with the high level of hardiness, the level of learning adaptation can be improved rapidly with the improvement of the support level of the teachers, which means that hardiness will enhance the impact of the teacher support on the learning adaptation of the students.

\section{RESULTS AND DISCUSSIONS}

The study found that the overall condition of college students' learning adaptation is good, which is consistent with the assumption of this study, and also with that of Sun and Fu (2016) and Fang (2008), showing that under the influence of family, school education and social environment, college students can well adapt to interpersonal relationship, learning activities and so on.

\section{Teacher Support has a Significant Positive Impact on Learning Adaptation}

This study found that teacher support for learning adaptation $(\beta=0.432, p<0.001)$ not only supports the influencing factor model of learning adaptation, but also accords with the results of previous studies. Reddy, 
Rhodes and Mulhall (2003) studies the relationship between teacher support and learning adaptation. Deci and Ryan (2000) further expand the teacher support the students perceived. They believe that learning in a teachersupported environment can enhance students' self-motivation and learning initiative, and promote students to actively mobilize their interest in learning, and, manage their learning behavior and time, use learning strategies, and be responsible for their learning results. In this study, teacher support plays an important role in learning adaptation for normal students who have been promoted directly from junior high school to university. As a result of young age, lack of understanding of the new environment, students and students have not yet established a good relationship of interaction, and the new collective needs a period of integration. In order to eliminate strangeness, the guidance and care of teachers is essential. Teachers should go to the dormitory to talk with the students, understand the students' dynamics, resolve students' inadaptability to the new collective life, and guide students' adverse psychological reactions. According to Brophy, Maras and Wang (2015), among so many teacher supports, a good teacher-student relationship is to help students overcome the adverse environmental impact and the most effective strategies to cultivate and stimulate students' learning motivation. Among these students from rural areas or towns, their learning habit of examination-oriented education in rural or township middle schools has affected the adaptation to open-ended autonomous learning and research-based learning in universities, which requires teachers to encourage learning. Teachers should recommend some good learning experiences and professional bibliographies to guide students to learn independently and build confidence so that they can gradually complete the transition from junior high school to college. The teacher should pour certain emotion into each student, and let each of them feel the concern from the teacher. Only with the emotion education can they establish a harmonious teacher-student relationship, can the students learn in pleasure and learn to adapt to college life.

\section{Hardiness has a Significant Positive Effect on Learning Adaptation}

This study found that hardiness for learning adaptation $(\beta=0.285, \mathrm{p}<0.001)$, which has a significant positive predictive effect and good fitting degree index of the model, not only supports the influencing factor model of learning adaptation, but was also positively correlated with school adaptation, according to Sun and Fu (2016).

The result is even more supportive of a widely accepted view: When used as a personality trait, hardiness can protect the individual from the adverse effects of stress or adversity. It is a protective factor of the individual's mental health (Collishaw et al. 2007). In the related study, the positive personality factors have a certain influence on students' learning adaptation. The study of college students in China by Wang et al. (2016) shows that there is a significant positive correlation between active personality and academic adaptation. When students encounter certain difficulties, some choose negative response, while others choose positive actions, trying hard to find a strategy to solve the problem. Hardiness is the potential hidden in each individual's heart. When each person is externalized, there are different forms of expressions, with some strong, while others stubborn or paranoid, which are all responses to external stimuli. Smith, Young, and Lee (2004) also pointed out that an individual with a strong hardiness should have the ability to "sustain physical and psychological suffering; have the strength - the ability to resist stress, and difficulty; be brave enough - the quality of courage, boldness and adventure; have the ability to exert power and influence". The study of this variable begins with the medical feedback to the health of the patient. This study was used to demonstrate the stress response of individuals to various difficulties in adaptive learning. In this study, the only child showed a good and hardy personality in learning adaptation, which improves the concerns about the only child, fearing that family indulgence will make children cowardly and lose their positive personality. It should be recognized that hardiness is a positive personality trait and a protective factor of learning adaptation, which not only helps to improve students' learning adaptation level, but also buffers the negative effects of bad factors. The university stage is the transition from school to the society, and student's hardiness still has greater plasticity. Schools should pay more attention to the cultivation and improvement of students' hardiness, and actively explore the ways and means of cultivating hardiness, such as strengthening physical exercise, carrying out frustration education, carrying out stress training, organizing group psychological guidance, and so on.

\section{The Moderation Function of Hardiness in Teacher Support and Learning Adaptation}

The results show that hardiness can enhance the influence of teacher support on learning adaptation. The results of this study and the related studies were confirmed (Sun \& Fu, 2016). The results of regulatory effect analyses showed that the relationship between stress and school adaptation was regulated by the hardiness of college students. Under low stress, the school adaptation level of college students with great hardiness is obviously better than that with low hardiness. First of all, students with great hardiness are more adaptable to study with the support of teachers. Secondly, students with low hardiness were gradually improved under the support of teachers (Garmezy, Masten, \& Tellegen, 1984). The conditional model of psychological hardiness confirms that some traits of the individual can reduce or regulate the negative effects of risk factors. As a positive personality trait, hardiness can resist the negative influence of the external environment, and it is the aspect of the teacher's teaching that should be concerned and paid attention to. 


\section{CONCLUSION}

\section{The following conclusions are drawn from this study:}

(1) Teacher support has a significant positive effect on learning adaptation;

(2) Hardiness has a significant positive effect on learning adaptation;

(3) The Regulation of hardiness between teachers support and learning adaptation.

Research limitations and recommendations:

There are still some problems in this study, which need to be further improved in the future: Firstly, the study sample is only limited to a college in Hunan, which is of certain limitations. Secondly, as a cross-sectional study, it is difficult to define the causal relationship between the variables in a strict sense. In the future, the in-depth research should be carried out in combination with the longitudinal study.

\section{REFERENCES}

Abdollahi, A., Talib, M.A., Yaacob, S. N., \& Ismail, Z. (2015). The role of hardiness in decreasing stress and suicidal ideation in a sample of undergraduate students. Journal of Humanistic Psychology, 55(2), 202-222. https://doi.org/10.1177/0022167814543952

Ahmed, W., Minnaert, Æ. A., Van der Werf, G., \& Kuyper, Æ. H. (2010). Perceived social support and early adolescents 'achievement: The mediational roles of motivational beliefs and emotions. Journal Youth and Adolescence, 39, 36-46. https:/ / doi.org/10.1007/ s10964-008-9367-7

Ansong, D., Okumu, M., Bowen, G. L., Walker, A. M., \& Eisensmith, S. R. (2017). The role of parent, classmate, and teacher support in student engagement: evidence from ghana. International Journal of Educational Development, 54, 51-58. https://doi.org/10.1016/j.ijedudev.2017.03.010

Assor, A., Kaplan, H., \& Roth, G. (2002). Choice is good, but relevance is excellent: autonomy-enhancing and suppressing teacher behaviours predicting students' engagement in schoolwork. British Journal of Educational Psychology, 72(2), 261-78. https://doi.org/10.1348/000709902158883

Che, W. (2001). Encyclopedia of Psychological Counseling. Hangzhou: Zhejiang Science and Technology Press, 52.

Chen, J. (2004) On social support and school adaptation of freshmen. Journal of Wuhan University of Science and Technology (Social Science Edition), 6(4), 69-72.

Chen, Y., \& He, Y. (2005) Psychological adaptation and countermeasures of postgraduate students in colleges and universities. Journal of Architectural Education in Institutions of Higher Learning, 14(1), 116-118.

Collishaw, S., Goodman, R., Pickles, A., \& Maughan, B. (2007). Modelling the contribution of changes in family life to time trends in adolescent conduct problems. Social Science $\mathcal{E}$ Medicine, 65(12), 2576. https://doi.org/10.1016/j.socscimed.2007.06.010

Deci, E. L., \& Ryan, R. M. (1985). Cognitive Evaluation Theory. Intrinsic Motivation and Self-Determination in Human Behavior. Springer US.

Deci, E. L., \& Ryan, R. M. (2004). Intrinsic motivation and self-determination in human behavior. Encyclopedia of Applied Psychology, 3(2), 437-448. https:/ / doi.org/10.1016/B0-12-657410-3/00689-9

Dill, D. D. (1999). Academic accountability and university adaptation: the architecture of an academic learning organization. Higher Education, 38(2), 127-154. https:/ / doi.org/10.1023/ A:1003762420723

Fang, C. (2008). Research on the present situation of social adaptation of contemporary college students (Master's Thesis), Yunnan Normal University, Kunming, 38-39.

Feng, W., \& Yang, J. (2005) A Comparative study on the learning adaptability of higher vocational college students and ordinary college students. Chinese Journal of Special Education, 11(5), 151-166.

Garcia-Reid, P., Reid, R. J., \& Peterson, N. A. (2005). School engagement among Latino youth in an urban middle school context. Education \& Urban Society, 37(3), 257-275. https:/ / doi.org/10.1177/0013124505275534

Garmezy, N., Masten, A. S., \& Tellegen, A. (1984). The study of stress and competence in children: a building block for developmental psychopathology. Child Development, 55(1), 97-111. https:/ / doi.org/10.2307/1129837

Ghorbani, N., Watson, P. J., \& Morris, R. J. (2000). Personality, stress, and mental health: Evidence of relationships in a sample of Iranian managers. Personality and Individual Differences, 28, 647-657. https:/ / doi.org/10.1016/S0191-8869(99)00128-2

He, F., \& Hu, M. (2017). The compilation of school adaptation scale for the five-year normal students. China Journal of Health Psychology, 25(5), 740-744. 
Herrero Romero, R., Hall, J., \& Cluver, L. (2018). Exposure to violence, teacher support, and school delay amongst adolescents in South Africa. British Journal of Educational Psychology, (October 2016). https:/ / doi.org/10.1111/bjep.12212

Hou, J. (2014) Compilation of School Adaptation Scale for College Students. China Journal of Health Psychology, (8), 1177-1181.

Huang, J. (2015). Hardiness, perceived employability, and career decision self-efficacy among Taiwanese college students. Journal of Career Development, 42(4), 311-324. https:/ / doi.org/10.1177/0894845314562960

Jia, X. (2001) The essence and mechanism of psychological adaptation. Journal of Tianjin Normal University (Social Science Edition) (1), 1923.

Judge, T. A., \& Bono, J. E. (2001). Relationship of core self-evaluations traits--self-esteem, generalized self-efficacy, locus of control, and emotional stability--with job satisfaction and job performance: a meta-analysis. Journal of Applied Psychology, 86(1), 80-92. https:/ / doi.org/10.1037/0021-9010.86.1.80

Kobasa, S. (1979). Personality and resistance to illness. American Journal of Community Psychology, 7(4), 413-423. https:/ / doi.org/10.1007/BF00894383

Kobasa, S. (1979). Stressful life events, personality and health: An enquiry into hardiness. Journal of Personality and Social Psychology, 37, 1-11. https:/ / doi.org/10.1037/0022-3514.37.1.1

Kobasa, S. (1982). The hardy personality: Toward a social psychology of stress and health. In G. S. Sanders \& J. Suls (Eds.), Social psychology of health and illness. Hillsdale, NJ: Lawrence Erlbaum.

Kobasa, S. C., Maddi, S. R., \& Kahn, S. (1982). Hardiness and health: A perspective study. Journal of Personality and Social Psychology, 42(1), 168-177. https:/ / doi.org/10.1037/0022-3514.42.1.168

Kobasa, S., Maddi. S., \& Kahn, S. (1982). Hardiness and health: A prospective study. Journal of Personality and Social Psychology, 42, 168-177. https://doi.org/10.1037/0022-3514.42.1.168

Lee, P., \& Bierman, K. L. (2015). Classroom and teacher support in kindergarten: associations with the behavioral and academic adjustment of low-income students. Merrill Palmer Q, 61(3), 383-411. https:/ / doi.org/10.13110/merrpalmquar1982.61.3.0383

Leflot, G., van Lier, P. A., Verschueren, K., Onghena, P., \& Colpin, H. (2011). Transactional associations among teacher support, peer social preference, and child externalizing behavior: a four-wave longitudinal study. Journal of Clinical Child E Adolescent Psychology, 40(1), 87-99. https:/ / doi.org/10.1080/15374416.2011.533409

Lentillon, V., Cogérino, G., \& Kaestner, M. (2006). Injustice in physical education: gender and the perception of deprivation in grades and teacher support. Social Psychology of Education, 9(3), 321-339. https:/ / doi.org/10.1007/s11218-005-5122-Z

Li, W., Zou, H., \& Zhao, X. (2003) Relationship between social support and school adaptation among junior high school students. Psychological Development and Education, 19(3), 73-81.

Lu ,G., \& Liang, B. (2008). On relationship between hardiness, psychological stress and psychological symptoms of college students. Chinese Journal of Behavioral Medical Science, 17(8), 737-739.

Maddi, S. (2002). The story of hardiness: Twenty years of theorizing, research, and practice. Consulting Psychology Journal: Practice and Research, 54(3), 175-185. https:/ / doi.org/10.1037/1061-4087.54.3.173

Maddi, S. (2006). Hardiness: The courage to grow from stresses. Journal of Positive Psychology, 1, 160-168. https:// doi.org/10.1080/17439760600619609

Maddi, S. R., Harvey, R. H., Khoshaba, D. M., Faazel, M., \& Resurreccion, N. (2012). The relationship of hardiness and some other relevant variables to college performance. Journal of Humanistic Psychology, 52(2), 190-205. https:/ / doi.org/10.1177/0022167811422497

Maddi, S. R., Harvey, R. H., Khoshaba, D. M., Fazel, M., \& Resurreccion, N. (2012). The Relationship of Hardiness and Some Other Relevant Variables to College Performance. Journal of Humanistic Psychology, 52(2) 190-205. https:/ / doi.org/10.1177/0022167811422497

Malec, D., \& NiksIc', E. (2015). Analysis of differences between untalented students and students with sports talent in personality dimensions and teacher support. Acta Kinesiologica, 28(8), 1507-1514.

McVicar, A. (2003). Workplace stress in nursing: A literature review. Journal of Advanced Nursing, 44, 633-642. https:/ / doi.org/10.1046/j.0309-2402.2003.02853.x

Onuoha, U. C. (2015) Evidence of Academic Self Efficacy, Perceived Teacher Support, Age and Gender as Predictors of School Burnout. Global Journal of Human-Social Science: Arts E Humanities - Psychology, 15(2).

Opdenakker, M. C. (2015). Teacher support versus thwart: their importance to motivation, self-regulation and need satisfaction. Lancet, 347(347), 394-395. 
Ouyang, D. (2005). On relationship between teacher expectation, academic self-concept, students' perception of teacher support behavior and academic achievement (Doctoral dissertation), Guangxi Normal University.

PPitzer, J., \& Skinner, E. (2016). Predictors of changes in students' motivational resilience over the school year: the roles of teacher support, self-appraisals, and emotional reactivity. International Journal of Behavioral Development, 41(1). https:// doi.org/10.1177/0165025416642051

Reddy, R., Rhodes, J. E., \& Mulhall, P. (2003). The influence of teacher support on student adjustment in the middle school years: a latent growth curve study. Dev Psychopathol, 15(1), 119-138. https:/ / doi.org/10.1017/S0954579403000075

Smith, N., Young, A., \& Lee, C. (2004). Optimism, health-related hardiness and well-being among older Australian women. Journal of Health Psychology, 9(6), 741. https:/ / doi.org/10.1177/1359105304045373

Sun, Q., \& Fu, Z. (2016). The relationship between college students' stress and school adaptation: the adjustment of hardiness. Advances in Psychology, 6(11), 1149-1157. https:/ / doi.org/10.12677/ AP.2016.611145

Tan, Y. (2011). A study on the relationship between psychological tenacity, shyness, self-efficacy and social support of competitive sports talents (Master's degree thesis), Shandong Normal University.

Tao, S. (2003) A study on the relationship between social support and college students' admission adaptation. Journal of Psychological Science, 26(5), 908-909.

Wang, W, Lei, L, \& Wang, X. (2016). The influence of college students' Initiative on academic achievement: the intermediary role of academic self-efficacy and learning adaptation. Psychological Development and Education, 32( 5),579-586.

Wentzel, K. R. (2009). Students' relationships with teachers as motivational contexts. In K. R. Wentzel \& A. Wigfield (Eds.), Handbook of motivation at school (pp. 301-322). New York, NY: Routledge. https:/ / doi.org/10.4324/9780203879498

Xiao, N. (2016). On relationship between teacher support, self-determination motivation and school adaptation of medical students (Doctoral dissertation), Henan University.

$\mathrm{Xu}, \mathrm{F}$. (2000). Sociopsychological analysis on the cultivation of human adaptability. Educational Research and Experiment, (6).

$\mathrm{Yu}$, L. (1997). On the psychological adaptation of freshmen. Journal of Capital Normal University (Social Science Edition), (4), 108-112.

Yu, X. (2007). A Study on the adaptability and personality of freshmen. China Journal of Health Psychology, 15(5), 415417.

Zhang, D., Feng, Z., Guo, C., \& Chen, X. (2000). Some questions on the study of students' psychological quality. Journal of Southwest Normal University, (3).

Zheng, R. (1994). Middle school students' psychological diagnosis. Jinan, China: Shandong Education Press.

Zhou, H., \& Long, L-R. (2004). Statistic test and control of common method biases. Advances in Psychological Science, 12(6), 942-949.

Zhu, Z. (1999). Dictionary of Psychology. Beijing Normal University Press, 337.

\section{http://www.ejmste.com}

